OPEN ACCESS

Edited by:

Xinping Zhang,

Beijing University of Technology,

China

Reviewed by:

Shengfei Feng,

Capital Normal University, China

Nirmal Mazumder,

Manipal Academy of Higher

Education, India

${ }^{*}$ Correspondence:

Jin Li

lijin@ise.neu.edu.cn

Yong Zhao

zhaoyong@ise.neu.edu.cn

Specialty section:

This article was submitted to Optics and Photonics,

a section of the journal

Frontiers in Physics

Received: 29 August 2020

Accepted: 30 October 2020

Published: 27 November 2020

Citation:

Cai Y, Li M, Wang M, Li J, Zhang Y and Zhao Y (2020) Optical Fiber Sensors for Metal lons Detection Based on Novel

Fluorescent Materials.

Front. Phys. 8:598209.

doi: $10.3389 /$ fphy.2020.598209

\section{Optical Fiber Sensors for Metal Ions Detection Based on Novel Fluorescent Materials}

\author{
Yi Cai ${ }^{1,2}$, Ming $L i^{1}$, Minghao Wang ${ }^{1}$, Jin $L i^{2 *}$, Ya-nan Zhang ${ }^{2}$ and Yong Zhao ${ }^{1,2 *}$ \\ ${ }^{1}$ School of Control Engineering, Hebei Key Laboratory of Micro-Nano Precision Optical Sensing and Measurement Technology, \\ Northeastern University at Qinhuangdao, Qinhuangdao, China, ${ }^{2}$ College of Information Science and Engineering, Northeastern \\ University, Shenyang, China
}

Recently, novel fluorescent probes based on biomaterials and luminescent nanomaterials for metal ions attract tremendous attentions, owing to their advantages of simple operation, high sensitivity and rapid response for metals detection. Immobilized on the optical fiber sensor, fluorescent probes reveal the advantages while facing outdoor detection challenges. Therefore, numerous fluorescent optical fiber sensors for metal ions have been developed for online and in-situ detection to predict and prevent the environmental problems. Differ from refractometer-based fiber sensors, the structures of the fiber sensors based on fluorescent materials are usually simple, and the characters of the materials and the fabrication processes of fiber sensors are more significant to the sensing performances. This paper summarized the studies of optical fiber sensors for metal detection based on novel fluorescent materials to help researchers get the highlights of recent notable advancements and obtain the better potential prospects.

Keywords: fluorescent probes, in-situ detection, metal ions, fiber sensors, luminescent nanomaterials

\section{INTRODUCTION}

Heavy metal pollution leads to serious harm to the environment and human beings, and it becomes a notable urgent worldwide problem $[1,2]$. In order to estimate the degree of pollution, the development of rapid and sensitive methods for metals detection is a hot issue for the researchers [3-5]. In general, the most sensitive metals detection methods for laboratory analysis are atomic spectrometry and inductively coupled plasma-mass spectrometry [6, 7]. However, the conventional instruments are too bulky to implement online and emergency analysis.

Differ from these instrumental techniques, fluorescent probe techniques attract tremendous attentions because of simple operation process, rapid response and high sensitivity for metal ions sensing [8]. With the prosperity of fluorescent materials, biomaterials and luminescent nanomaterials are widely used as fluorescent probes for metal detection recently $[9,10]$. However, the main problem of fluorescent probes encounters is that they cannot applied for real time detection because the luminescent materials or fluorescence labeling materials have to be mixed with aqueous samples.

Concerning this issue, some researchers have immobilized the fluorescent materials on the surface of the fiber probe because the optical fibers can deliver the valuable information for real time sensing. With the positive aspects of long-life spans and immune to electromagnetic interference, the fiber sensors can also be applied in field and emergency analysis [11, 12]. Usually, the fluorescent fiber sensing system is consist of an excitation light source, a fiber with the sensor probe, a spectrometer and a computer. The excitation light propagates along the optical fiber and 


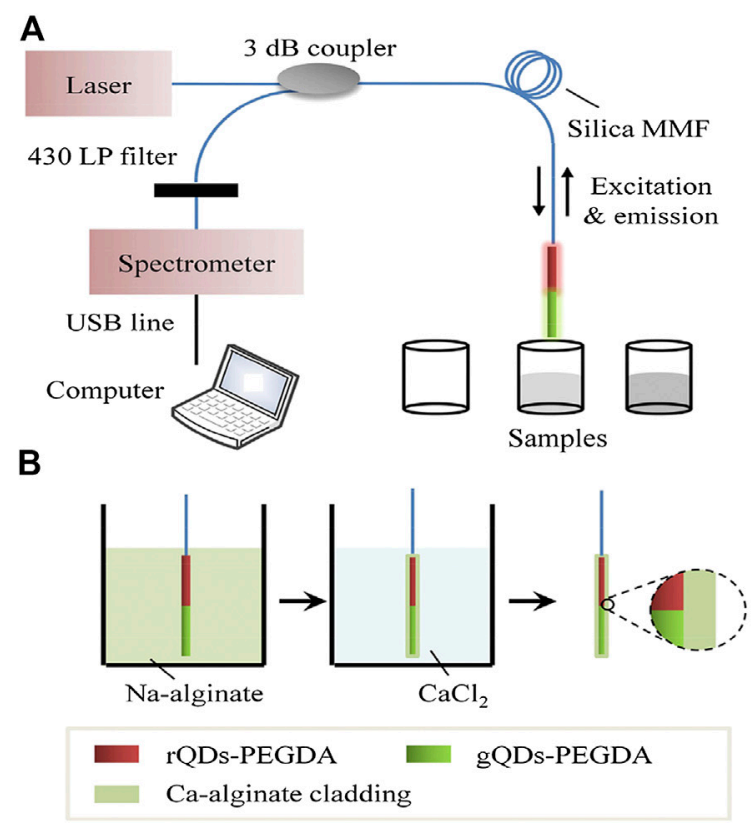

C

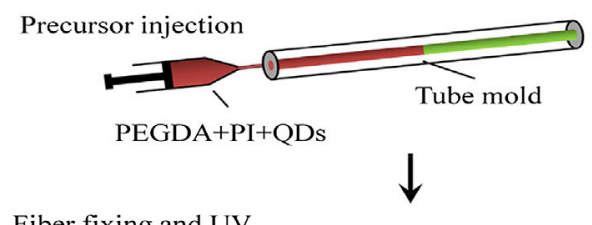

Fiber fixing and UV UV lamp polymerization

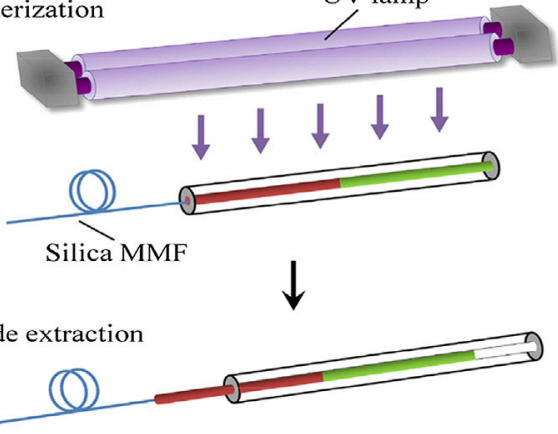

FIGURE 1 | Optical setup for sensing of $\mathrm{Fe}^{3+}$ ions based on the ratiometric fiber sensor (A); Cladding encapsulation (B); Fabrication steps of the fiber core doped with QDs (C). [24].

the sensor probe with fluorescent materials is designed to give fluorescent response back through the fiber. The spectrometer records the fluorescent intensities and the computer performs the data analysis. The fluorescence quenching caused by the reactions between target metals and fluorescent materials immobilized on the fiber tip provides quantitative basis for sensing. The static quenching of fluorescence by metal ions concentration [Q] is described using the Stern-Volmer equation:

$$
\frac{\mathrm{I}_{0}}{\mathrm{I}}=1+\mathrm{K}_{\mathrm{SV}}[\mathrm{Q}]
$$

where $I_{0}$ is the fluorescence intensity without metal ion, $I$ is the fluorescence intensity observed in the presence of a metal ion and $\mathrm{K}_{\mathrm{SV}}$ is the static (conditional stability constant) Stern-Volmer constant [13]. It may helpful to refer to Figure 1A to know sketchily how the pieces work together.

In this mini-review, the fiber sensors for heavy metal ions detection based on novel fluorescent materials are summarized, and some related key techniques have also been discussed.

\section{THE BIOMATERIALS-BASED FIBER SENSORS}

It is shown that some biomaterials, such as protein, bacterial and oligodeoxyribonucleotide can bind heavy metal ions specifically and their derivatives can be used as fluorescent probes. Based on the fluorescence labeling biomaterials, a number of chemical fluorescent fiber sensors for heavy metal ions detection have been designed and fabricated.

\section{Protein Labeled Biosensor}

The protein labeled fluorescent biosensor for metals detection can be traced back to almost 20 years ago. At first, the fiber is independent from the fluorescent membrane and simply used for light propagation. It has been turned out that the fluoresceinlabeled calmodulin (F-CaM) forms fluorescent chelate with specific metals [14]. have developed a fluorescent fiber sensor for $\mathrm{Ca}^{2+}$ and $\mathrm{Eu}^{3+}$ detection assisted by the dialysis membrane. The dialysis membrane is employed to entrap $\mathrm{pH} 7.0$ buffer solution with F-CaM at the end of the fiber bundle. The detection limits of $\mathrm{Ca}^{2+}$ and $\mathrm{Eu}^{3+}$ are $5 \times 10^{-8}$ and $1.0 \times 10^{-15} \mathrm{M}$, respectively. Zeng et al. [15] have reported a fluorescencebased fiber with protein molecule sensor transducers. The fluorophore is labeled on the enzyme human carbonic anhydrase II site and attached to the end of the fiber for $\mathrm{Cu}^{2+}$ ions detection. The detection limit of the proposed sensor is as low as $0.1 \mathrm{pM}$. The sensor can realize $\mathrm{Cu}^{2+}$ detection in marine chemistry.

\section{Nucleic Acids-Based Fiber Sensors}

The affinitive and specific reactions between oligodeoxyribonucleotide derivatives and some metal ions have been proved. As early as 2004, researchers have found that $\mathrm{Hg}^{2+}$ can bind between two T-bases of DNA fragment and then $\mathrm{T}-\mathrm{Hg}^{2+}-\mathrm{T}$ hairpin structure forms [16]. Based on this specific binding [17], have applied the $\mathrm{T}-\mathrm{Hg}^{2+}-\mathrm{T}$ hairpin structure to the fiber sensor development for $\mathrm{Hg}^{2+}$ online detection. The higher $\mathrm{Hg}^{2+}$ concentration makes less fluorescence-labeled cDNA bind to the surface of fiber tip and a lower fluorescence response is obtained for quantitative analysis. Later [18], have also developed a fluorescent biosensor based on the $\mathrm{T}-\mathrm{Hg}^{2+}-\mathrm{T}$ hairpin structure 


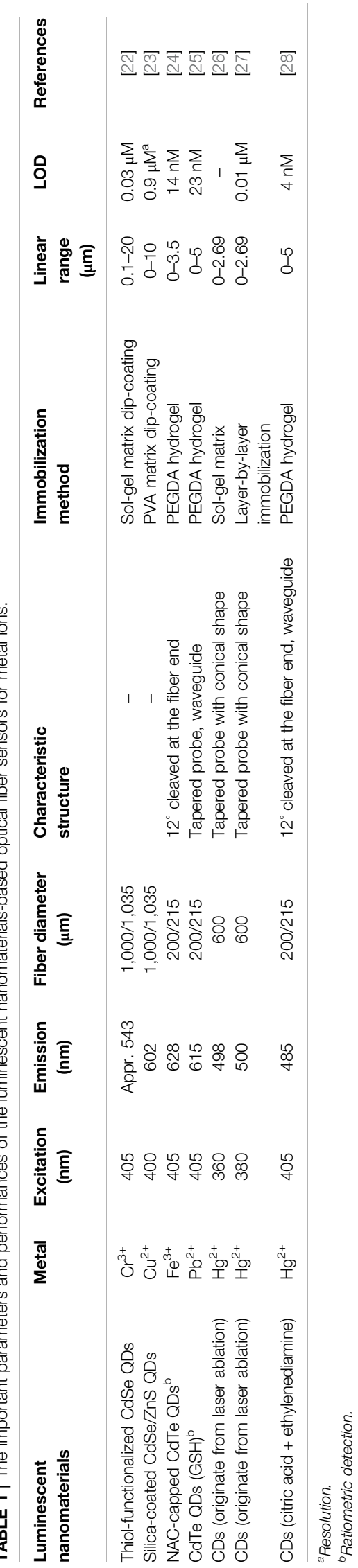

for $\mathrm{Hg}^{2+}$ detection. In the above experiments, the detection limits are both low and can reach 2.1 and $1.06 \mathrm{nM}$, respectively.

On the other hand, the DNAzymes can be cleaved by $\mathrm{Pb}^{2+}$ and the fluorescent labeled fragments release. Based on the changes of fluorescence intensity caused by $\mathrm{Pb}^{2+}$, an optical fiber sensor has been developed for $\mathrm{Pb}^{2+}$ detection in aqueous samples [19]. Later, a two-step "turn-on" evanescent-wave fiber sensor has been developed for duple metals $\left(\mathrm{Hg}^{2+}\right.$ and $\left.\mathrm{Pb}^{2+}\right)$ rapid online detection for environmental water samples [20]. The proposed biosensor shows superior performance and it can be regenerated for dozens of times.

It is shown that the fluorescent biosensors based on functional nucleic acids have high sensitivity and specificity. The application of the biosensor for $\mathrm{Hg}^{2+}$ and $\mathrm{Pb}^{2+}$ detection shows great potential for on-site environmental monitoring. However, the deficiency of the specific reactions between metal species and DNA derivatives limits the detection scope. In addition, long preparation periods and delicate operations are needed for these sensors due to the DNA derivatives are covalently immobilized on the fiber surfaces in the existing literatures.

\section{LUMINESCENT NANOMATERIALS-BASED FIBER SENSORS}

Semiconductor-type quantum dots (QDs) and carbon dots (CDs) show many significant advantages compared with conventional fluorescent organic dyes. As fluorescent probes for metals sensing, QDs and CDs can specifically detect $\mathrm{Hg}^{2+}, \mathrm{As}^{3+}, \mathrm{Pb}^{2+}$, $\mathrm{Cr}^{6+}, \mathrm{Cd}^{2+}, \mathrm{Fe}^{3+}, \mathrm{Zn}^{2+}, \mathrm{Cu}^{2+}$, etc [21]. It is a good idea to combine luminescent nanomaterials with optical fibers for online and insitu detection. Table 1 summarizes some important parameters and the analytical performances of the reported luminescent nanomaterials-based optical fiber sensors. Although red QDs or CDs are needed in the field of bioimaging and biodiagnosis, the more available blue or green QDs or CDs are enough for coupling with the fiber sensors. Moreover, it is illustrated that the sensors show high selectivity although they are applied to a minority of metal ions.

\section{Semiconductor-Type Quantum Dots}

The quantum dots (QDs) with positive aspects of high luminescence quantum yield, good photostability, broad excitation band, narrow emission band, size-dependent emission wavelength and large effective Stokes shift have attracted extensive attention recently.

A sensor based on QDs for $\mathrm{Cr}^{3+}$ detection is developed by Sung et al. [22]. The fiber probe is coated with water-soluble CdSe QDs by sol-gel matrix on the surface. This group has also reported a fluorescent sensor with high performance for copper ions detection. The $\mathrm{CdSe} / \mathrm{ZnS} @ \mathrm{SiO}_{2}$ nanostructures are formed by encapsulating monodispersed hydrophobic CdSe/ZnS nanoparticles in silica shells and then they are coated on the tip of the fiber by polyvinyl alcohol polymer [23]. The porous silica shells here prevent the aggregation of the nanoparticles and provide better chemical stability with wide $\mathrm{pH}$ value. The design of structural nanoparticles is used to provide better 
chemical stability with solution environment. The method of ratiometric detection makes the sensors more applicable and reliable in different environmental conditions. Zhou et al. [24] have developed a reliable fluorescent sensor for selective and online detection of $\mathrm{Fe}^{3+}$ through ratiometric detection method. The set-up of the proposed ratiometric sensing system is shown in Figure 1A. The red emissive QDs with N-Acetyl-L-cysteine can be quenched selectively by $\mathrm{Fe}^{3+}$, while the green emissive QDs with thioglycolic acid are immune to $\mathrm{Fe}^{3+}$ that the fluorescence emission remains stable. The ratio of the red emission intensities and green emission intensities would provide a built-in correction for environmental effects. As shown in Figure 1B, the two types of CdTe QDs doped PEGDA hydrogel are immobilized on the fiber probe for real time sensing. The fabrication steps of the fiber probe are shown in Figure 1C. The QDs doped polymerized hydrogel (PEGDA) can be immobilized on the fiber in only $5 \mathrm{~min}$ under UV irradiation. Guo et al. [25] have designed a waveguide ratiometric biosensor with the advantages of soft and biocompatible to sense $\mathrm{Pb}^{2+}$ rapidly and sensitively. In this work, the fluorescence of CdTe QDs with GSH is selectively quenched by $\mathrm{Pb}^{2+}$, while the QDs with TGA show stable emission when dozens of metal ions adding into samples including $\mathrm{Pb}^{2+}$.

With the development of the fluorescent fiber sensor, the higher requirement for sensing is putting forward. To response the problem of results deviation influenced by some environmental factors, the researchers give appropriate solutions.

\section{Carbon Dots}

Carbon nanomaterials are excellent for their environmental friendliness and abundant reserves. A carbon dots (CDs)based optical fiber sensor for $\mathrm{Hg}^{2+}$ detection has been reported [26]. In the experiment, the CDs, which are specific to $\mathrm{Hg}^{2+}$, are synthesized and mixed with sol-gel matrix and immobilized to the surface of tapered fiber tip. The fiber tip is immersed in $40 \%$ HF solution for luminescence collection and excitation efficiency enhancement. However, the preparation of the sol-gel films on the surface of sensing probes takes several days. Later, a single optical fiber sensor with layer-by-layer carbon dots immobilization for $\mathrm{Hg}^{2+}$ has been reported by the same research group [27]. In this work, the immobilization process can be accomplished in hours. It is turned out that PEGDA hydrogel doped with fluorescent materials can be solidified under UV irradiation in minutes. Guo et al. [28] have reported a fluorescent fiber sensor based on CDs incorporated nanocomposite hydrogels for $\mathrm{Hg}^{2+}$ sensing. The coupled silica fiber end has been cleaved at an appropriate angle to suppress the back reflection and injected into the slab waveguide which is consist of $40 \%$ PEGDA doped with fluorescent carbon dots.

\section{REFERENCES}

1. Zheng S, Wang Q, Yuan Y, Sun W. Human health risk assessment of heavy metals in soil and food crops in the Pearl River Delta urban agglomeration of China. Food Chem (2020) 316, 126213. doi:10.1016/j.foodchem.2020.126213

2. Ullah N, Mansha M, Khan I, Qurashi A. Nanomaterial-based optical chemical sesors for the detection of heavy metals in water: recent advances and
Besides the reliable results, the shorter preparing period is also expected. With the PEGDA hydrogel dip-coating, the more effective fabrication method is obtained. However, the sensing scope should be extended further.

\section{CONCLUSION}

The optical fiber sensors for metals detection based on novel fluorescent materials are summarized in the paper. The specific bindings between metal ions and the fluorescent materials are the foundation of the sensing. The employment of optical fiber makes online and in situ detection possible. Meanwhile, the development of the sensors encounters some problems. The key technique to solve the problems are also discussed. Therefore, the periods of materials immobilization toward the fiber tips can be shrank from days to minutes, the reliable detection results can be obtained with little environmental effect and the appropriate fiber structures are designed to deliver the fluorescence efficiently. The proposed sensors provide a promising approach for screening trace metal ions in environmental water samples. However, there are still some problems to be solved. For example, the application scope of the fluorescent materials-based fiber sensors should be expanded further. Could some sensors based on novel fluorescent materials be developed for sensing multiple metals simultaneously in the future? This does not just mean that the various nanomaterials fluorescent materials are immobilized on the fiber probes. It is important to design the structure of the fiber sensor probe, reform the sensing system and reconstruct the quantitative methods.

\section{AUTHOR CONTRIBUTIONS}

YC, ML, and MW conceived and performed the papers collection and manuscript writing; JL and $\mathrm{YZ}$ were involved in the paper writing; YZ was the supervisor and involved in the paper review and editing.

\section{FUNDING}

This work is financially supported by the Natural Science Foundation of China (21904017, 51805076) and Natural Science Foundation of Hebei Province (B2019501073), and the Fundamental Research Funds for the Central Universities (N182303035).

challenges. TrAC Trends Anal Chem (2018) 100, 155-66. doi:10.1016/j.trac. 2018.01.002

3. Li Y, Chen Y, Yu Y, Tian L, Wang Z. Portable and smart devices for monitoring heavy metal ions integrated with nanomaterials. TrAC Trends Anal Chem (2018) 98, 190-200. doi:10.1016/j.trac.2017.11.011

4. Kroukamp EM, Wondimu T, Forbes PBC. Metal and metalloid speciation in plants: overview, instrumentation, approaches and commonly assessed elements. TrAC Trends Anal Chem (2016) 77, 87-99. doi:10.1016/j.trac.2015.10.007 
5. Dalmieda J, Kruse P. Metal cation detection in drinking water. Sensors (2019) 19(23), 5134. doi:10.3390/s19235134

6. Clough R, Harrington CF, Hill SJ, Madrid Y, Tyson JF. Atomic spectrometry update: review of advances in elemental speciation. J Anal At Spectrom (2019) 34(7), 1306-50. doi:10.1039/c9ja90028d

7. Liu S, Yu YL, Wang JH. Advances in discharge-based microplasmas for the analysis of trace species by atomic spectrometry. J Anal At Spectrom (2017) 32(11), 2118-26. doi:10.1039/c7ja00279c

8 Chowdhury S, Rooj B, Dutta A, Mandal U. Review on recent advances in metal ions sensing using different fluorescent probes. J Fluoresc (2018) 28(4), 999-1021. doi:10.1007/s10895-018-2263-y

9. Li M, Wang Q, Shi X, Hornak LA, Wu N. Detection of Mercury(II) by Quantum dot/DNA/gold nanoparticle ensemble based nanosensor via nanometal surface energy transfer. Anal Chem (2011) 83(18), 7061-5. doi:10.1021/ac2019014

10. Tedsana $\mathrm{W}$, Tuntulani $\mathrm{W}$, Ngeontae W. A circular dichroism sensor for $\mathrm{Ni}^{2+}$ and $\mathrm{Co}^{2+}$ based on L-cysteine capped cadmium sulfide quantum dots. Anal Chim Acta (2015) 867, 1-8. doi:10.1016/j.aca.2014.12.004

11. Tan RX, Ibsen M, Tjin SC. Optical fiber refractometer based metal ion sensors. Chemosensors (2019) 7(4), 63. doi:10.3390/chemosensors7040063

12. Pawar D, Kale SN. A review on nanomaterial-modified optical fiber sensors for gases, vapors and ions. Microchim Acta (2019) 186(4), 253. doi:10.1007/ s00604-019-3351-7

13. Mohapatra S, Sahu S, Sinha N, Bhutia SK. Synthesis of a carbon-dot-based photoluminescent probe for selective and ultrasensitive detection of $\mathrm{Hg} 2+$ in water and living cells. Analyst (2015) 140(4), 1221-8. doi:10.1039/c4an01386g

14. Yang ST, Lee CS. Fabrication of fluorescent fiber-optic sensor using fluorescein-labeled calmodulin for the determination of $\mathrm{Ca}^{2+}$ and $\mathrm{Eu}^{3+}$. $J$ Ind Eng Chem (2002) 8(6), 557-63.

15. Zeng HH, Thompson RB, Maliwal BP, Fones GR, Moffett JW, Fierke CA. Real-time determination of picomolar free $\mathrm{Cu}(\mathrm{II})$ in seawater using a fluorescence based fiber optic biosensor. Anal Chem (2003) 75(24), 6807-12. doi:10.1021/ac0345401

16. Ono A, Togashi H. Highly selective oligonucleotide-based sensor for mercury(II) in aqueous solutions. Angew Chem Int Ed (2004) 43(33), 4300-2. doi:10.1002/anie. 200454172

17. Long F, Gao C, Shi HC, He M, Zhu AN, Klibanov AM, et al. Reusable evanescent wave DNA biosensor for rapid, highly sensitive, and selective detection of mercury ions. Biosens Bioelectron (2011) 26(10), 4018-23. doi:10. 1016/j.bios.2011.03.022

18. Wang RY, Zhou XH, Shi HC, Luo Y. T-T mismatch-driven biosensor using triple functional DNA-protein conjugates for facile detection of $\mathrm{Hg} 2+$. Biosens Bioelectron (2016) 78, 418-22. doi:10.1016/j.bios.2015.11.082
19. Yildirim N, Long F, He M, Gao C, Shi HC, Gu AZ. A portable DNAzyme-based optical biosensor for highly sensitive and selective detection of lead (II) in water sample. Talanta (2014) 129, 617-22. doi:10.1016/j.talanta.2014.03.062

20. Han S, Zhou X, Tang Y, He M, Zhang X, Shi H, et al. Practical, highly sensitive, and regenerable evanescent-wave biosensor for detection of $\mathrm{Hg}^{2+}$ and $\mathrm{Pb}^{2+}$ in water. Biosens Bioelectron (2016) 80, 265-72. doi:10.1016/j.bios.2016.01.070

21. Zhang JJ, Cheng FF, Li JJ, Zhu JJ, Lu Y. Fluorescent nanoprobes for sensing and imaging of metal ions: recent advances and future perspectives. Nano Today (2016) 11(3), 309-29. doi:10.1016/j.nantod.2016.05.010

22. Sung TW, Lo YL, Chang IL. Highly sensitive and selective fluorescence probe for $\mathrm{Cr}^{3+}$ ion detection using water-soluble CdSe QDs. Sensor Actuator B Chem (2014) 202, 1349-56. doi:10.1016/j.snb.2014.05.101

23. Sung TW, Lo YL. Highly sensitive and selective sensor based on silica-coated CdSe/ZnS nanoparticles for $\mathrm{Cu}^{2+}$ ion detection. Sensor Actuator B Chem (2012) 165(1), 119-25. doi:10.1016/j.snb.2012.02.028

24. Zhou M, Guo J, Yang C. Ratiometric fluorescence sensor for $\mathrm{Fe}^{3+}$ ions detection based on quantum dot-doped hydrogel optical fiber. Sensor Actuator B Chem (2018) 264, 52-8. doi:10.1016/j.snb.2018.02.119

25. Guo JJ, Huang HX, Zhou MJ, Yang CX, Kong LJ. Quantum dots-doped tapered hydrogel waveguide for ratiometric sensing of metal ions. Anal Chem (2018) 90(20), 12292-8. doi:10.1021/acs.analchem.8b03787

26. Goncalves HMR, Duarte AJ, Esteves da Silva JCG. Optical fiber sensor for $\mathrm{Hg}(\mathrm{II})$ based on carbon dots. Biosens Bioelectron (2010) 26(4), 1302-6. doi:10. 1016/j.bios.2010.07.018

27. Goncalves HMR, Duarte AJ, Davis F, Higson SPJ, Esteves da Silva JCG. Layerby-layer immobilization of carbon dots fluorescent nanomaterials on single optical fiber. Anal Chim Acta (2012) 735, 90-5. doi:10.1016/j.aca.2012.05.015

28. Guo J, Zhou M, Yang C. Fluorescent hydrogel waveguide for on-site detection of heavy metal ions. Sci Rep (2017) 7, 7902. doi:10.1038/s41598-017-08353-8

Conflict of Interest: The authors declare that the research was conducted in the absence of any commercial or financial relationships that could be construed as a potential conflict of interest.

Copyright () 2020 Cai, Li, Wang, Li, Zhang and Zhao. This is an open-access article distributed under the terms of the Creative Commons Attribution License (CC BY). The use, distribution or reproduction in other forums is permitted, provided the original author(s) and the copyright owner(s) are credited and that the original publication in this journal is cited, in accordance with accepted academic practice. No use, distribution or reproduction is permitted which does not comply with these terms. 